\title{
Museu Nacional de Brasília: Reflexões sobre a Interação Arquitetura x Estrutura
}

\author{
INOJOSA, Leonardo da Silveira Pirillo ${ }^{1}$ \\ BUZAR, Márcio Augusto Roma ${ }^{2}$ \\ DE GREGÓRIO, Marcos Henrique Ritter ${ }^{3}$ \\ ${ }^{1}$ Universidade de Brasília, Brasil. leonardo@inojosa.com.br \\ 22Universidade de Brasília, Brasil. buzar@unb.br \\ ${ }^{3}$ Centro Universitário de Brasília, Brasil. marcosritter@gmail.com
}

\begin{abstract}
Resumo
Obra mais recente de Oscar Niemeyer na Esplanada dos Ministérios, o Museu Nacional Honestino Guimarães, apresenta uma estrutura marcante, definidora de sua forma arquitetônica. O sistema estrutural, nitidamente baseado no conceito de cúpula, teve um papel essencial na determinação do desenho arquitetônico. Esta estreita interação entre arquitetura e estrutura é evidente na extensa obra produzida pelo arquiteto. Destaca-se, também, a influência de grandes engenheiros, como José Carlos Sussekind - autor do projeto estrutural da obra analisada - que, com participação efetiva desde a concepção dos projetos, proporcionou obras marcadas pelo arrojo estrutural e por grandes desafios tecnológicos. Por meio de análises feitas com o auxílio de ferramentas computacionais difundidos no meio acadêmico, foram coletados dados que permitiram entender como as escolhas das soluções estruturais pelo arquiteto e pelo engenheiro, durante o processo projetual, conseguiram os resultados estéticos monumentais e inovadores.
\end{abstract}

Palavras-Chave: Cúpula, Estrutura de Concreto, Projeto Estrutural, Sistemas estruturais.

\begin{abstract}
Oscar Niemeyer's most recent work at the Ministries Esplanade, the Honestino Guimarães National Museum presents an outstanding structure, which defines its architectural shape. The structural system, sharply based on the dome's concept, had an essential role at the determination of the architectural design. This close interaction between architecture and structure is evident in the extensive work produced by the architect. Also noteworthy is the influence of great engineers, like José Carlos Sussekind - the author of the estructural Project of the analyzed work with effective participation since the basic design of projects, provided structural works marked by boldness and technical challenges. Through analyzes with the aid of computational tools disseminated in academia,the collected data allowed to understand how the choices of structural solutions by architect and engineer during the design process, achieved the monumental and innovative aesthetic results.
\end{abstract}

Key-Words: Dome, Concrete Structure, Structural Project, Structural Systems. 


\section{Introdução}

O Museu Nacional Honestino Guimarães em Brasília, conhecido apenas como Museu Nacional, faz parte do Conjunto Cultural da República João Herculino, complexo que também abriga a Biblioteca Nacional Leonel de Moura Brizola e contará, também, com uma sala para orquestra sinfônica, uma ópera, um auditório para música de câmara, assim como possivelmente outros dois edifícios destinados atividades culturais. Sua inauguração aconteceu em 15 de Dezembro de 2006, mas sua história começa muito antes, já nos planos de Lúcio Costa para a Nova Capital.

O projeto arquitetônico concebido por Oscar Niemeyer para esse edifício foi desenvolvido para substituir um projeto originalmente criado em 1970 e que, por ser de uma estrutura mais ousada, foi considerado muito caro e posteriormente substituído por um projeto mais simples e barato.

Esse museu é um exemplo dos trabalhos mais recentes do arquiteto, quando Niemeyer já explora com muita experiência e simplicidade as qualidades estruturais do concreto armado. Na questão estrutural Niemeyer teve a importante contribuição do engenheiro José Carlos Sussekind, que esteve ao seu lado em diversas obras nos últimos 30 anos, entre elas o Museu Oscar Niemeyer em Curitiba e os projetos do Caminho Niemeyer em Niterói.

\section{Histórico}

Nos projetos originais do Plano Piloto de Brasília (Figura 1), apresentados pelo urbanista Lúcio Costa na década de 50, já estava prevista a construção de um museu.

Figura 1: Desenhos do Plano Piloto de Lúcio Costa 1957.
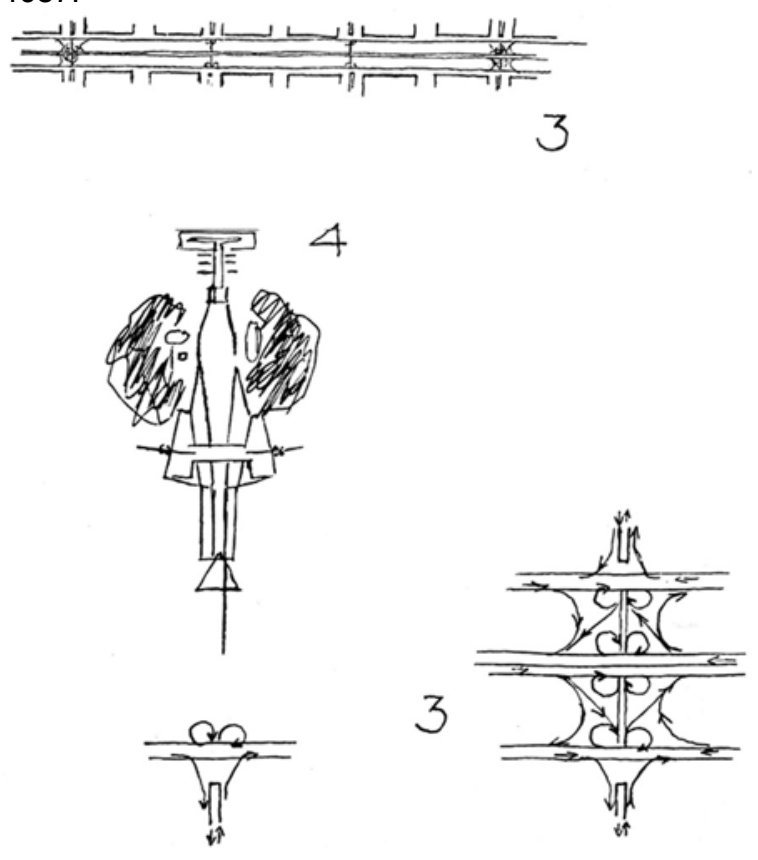

Fonte: Correio Brasiliense - 27 de fevereiro de 2002.
Porém, somente em 1970, na mesma época do projeto e construção do teatro Nacional, foi que surgiu o projeto do Conjunto Cultural. Esse primeiro projeto para o museu era bem diferente do que foi construído. Tratava-se de um edifício de 180 metros de comprimento com dois balanços de 70 metros para cada lado, suspenso na cobertura através de tirantes, e seria, provavelmente, um recorde na história do concreto armado (SUSSEKIND, 2002). Mas esse projeto ficou apenas no papel.

Em 1999, Oscar Niemeyer foi novamente chamado para reapresentar um projeto para Conjunto Cultural. A configuração urbanística proposta aproxima-se da definitiva: um conjunto de quatro prédios - Centro Musical, Cinemas, Museu e Biblioteca. O Museu e a Biblioteca ficaram dispostos na porção sul da esplanada e o Cinema e o Centro Musical, na porção norte (ainda não construídos). Uma passagem subterrânea unirá os dois lados, na qual ainda serão instaladas lojas e estacionamentos. (Figura 2).

Figura 2: Implantação do Conjunto Cultural.

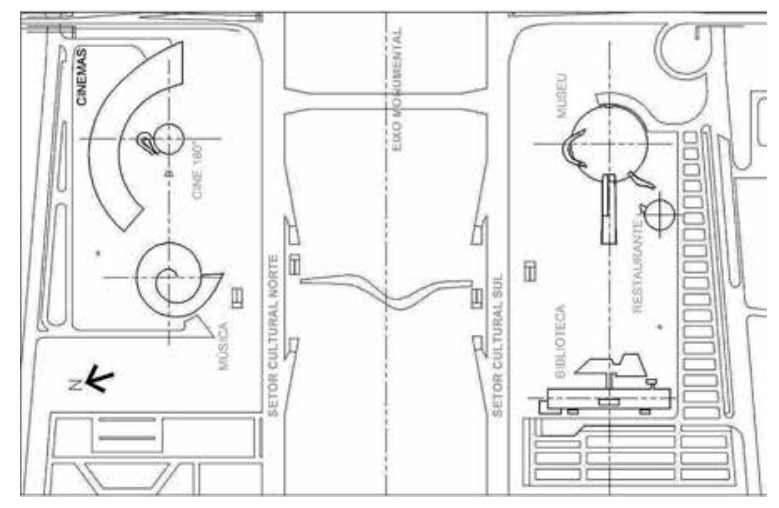

Fonte: Museu Nacional.

O projeto do Museu foi refeito, por razões de prazo e economia. Propôs-se uma cúpula de 40 metros de diâmetro e seu acesso se daria por uma rampa curva virada para a esplanada (SERAPIÃO, 2007). Essa cúpula abrigaria, além do museu, um restaurante panorâmico com jardim, o que induziria a duas aberturas assimétricas na parte superior da cúpula. Além disso, o projeto inicial teria janelas circulares na porção intermediária para iluminação dos espaços internos.

Uma nova versão, agora definitiva, foi proposta por volta de 2002. Nela, Niemeyer decidiu dobrar o tamanho da cúpula, segundo ele por notar, após estudos de uma maquete que representava quase toda a Esplanada dos Ministérios, que a escala desse edifício estava muito pequena diante do conjunto (SUSSEKIND, 2002), fazendo com que a cúpula passasse a ter o diâmetro de 80 metros. 
Foi então que, em 15 de Dezembro de 2006, data em que se comemorava o $99^{\circ}$ aniversário de Oscar Niemeyer, o Museu Nacional Honestino Guimarães foi inaugurado, com a exposição Niemeyer por Niemeyer na qual eram expostas fotografias e desenhos das principais obras do arquiteto em seus mais de 70 anos de carreira.

\section{Arquitetura}

Um espaço para exposições de grandes proporções é o elemento de destaque do interior do museu. O próprio Niemeyer assim descreve o espaço: "Não é um museu de obras fixas, mas um espaço contemporâneo, um museu de ideias, do experimental, que possa receber uma série de exposições e obras do Brasil e do mundo." (NIEMEYER, apud SUSSEKIND, 2002).

Além do salão de exposições, o edifício de 13.653 $\mathrm{m}^{2}$ de área construída ainda conta com dois auditórios, um para 700 e outro para 80 lugares; um mezanino com formas irregulares, suspenso e sustentado no teto da cúpula por meio de tirantes; dois elevadores para público e um elevador (plataforma) de carga; diversas salas para reservas técnicas e restauração e áreas para conservar obras não expostas. Com a mudança no projeto o restaurante passou a ocupar um anexo, de planta circular na parte de fora da cúpula e o estacionamento, agora ao ar livre, uma área mais a sudoeste do Setor.

A impactante arquitetura se expressa pela própria cúpula, que com 28 metros de altura se impõe na paisagem da esplanada e também pelos elementos que se destacam dela (Figura 3). A grande rampa do acesso principal, um plano inclinado de 52 metros de comprimento, virado para a Biblioteca dá unidade ao conjunto. Mas o elemento de maior destaque no exterior do Museu é a rampa que une o salão de exposições ao mezanino. Esta rampa sai do edifício fazendo um "passeio" pela esplanada e retornando ao interior no outro nível.

Figura 3: Vista externa do Museu Nacional.

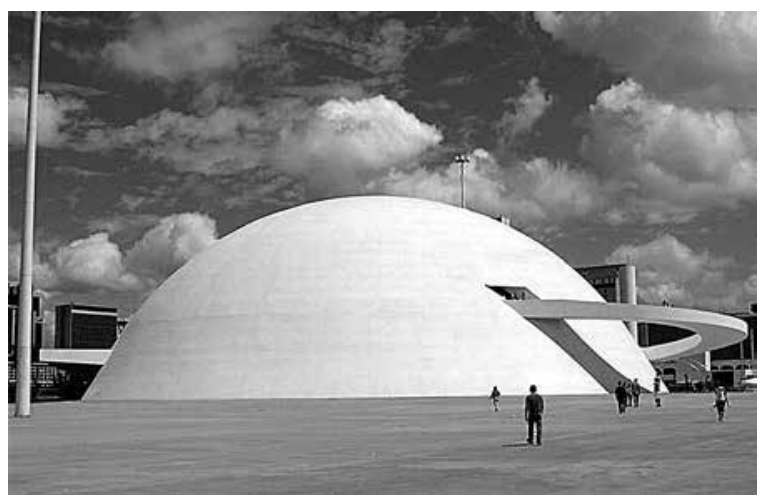

Fonte: foto do autor

Internamente (Figura 4), a arquitetura do museu também impressiona. $O$ nível do salão de ex- posições está localizado sobre uma grande laje totalmente livre e com um pé-direito monumental. O teto da cúpula é um grande "céu de concreto" para esse espaço que ainda abriga o mezanino em formato orgânico, cheio de curvas, para o qual se tem acesso por uma grande rampa, pela rampa externa e por elevadores. Esse mezanino está totalmente suspenso pelos tirantes na estrutura da própria cúpula, e por isso mantém o espaço do salão totalmente livre, sem pilares.

Figura 4: Vista Interna do Museu Nacional.

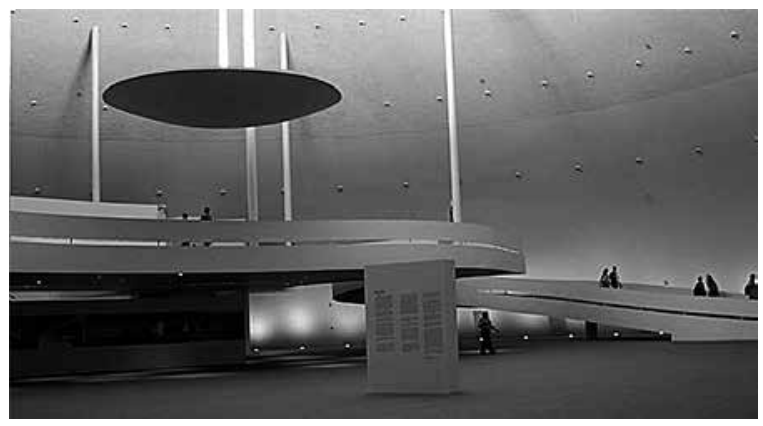

Fonte: Skyscrapercity.com

\section{Sistema Estrutural}

\subsection{Descrição do Sistema Estrutural}

$\mathrm{Na}$ arquitetura de Oscar Niemeyer é evidente a presença marcante do Sistema Estrutural na definição da forma e assim no resultado plástico da obra construída. Niemeyer gosta de valorizar o trabalho do engenheiro, no documentário "A Vida é um Sopro" de Fabiano Maciel ele mesmo diz:

Eu valorizei o trabalho do engenheiro. E lá em Brasília, quando uma estrutura se concluía a arquitetura já estava presente. (...) Arquitetura e Estrutura como coisas que nascem juntas e juntas devem se enriquecer. (Oscar Niemeyer, em "A Vida é um Sopro", Direção: Maciel, Fabiano - Europa Filmes, 2007)

A arquitetura do Museu Nacional segue essa linha de raciocínio. A forma plástica da arquitetura resulta de um sistema estrutural conhecido como cúpula. Nesse caso o arquiteto usou esse sistema de forma bem evidente, e ainda reforçou a estrutura da cúpula para nela "pendurar" o mezanino e a rampa externa.

A Cúpula é uma associação contínua arco $\mathrm{x}$ arco, que pode ser obtida pela repetição radial sucessiva de arcos muito próximos uns aos outros, como mostra a Figura 5. 
Figura 5: Cúpula formada pela sucessão radial de arcos.

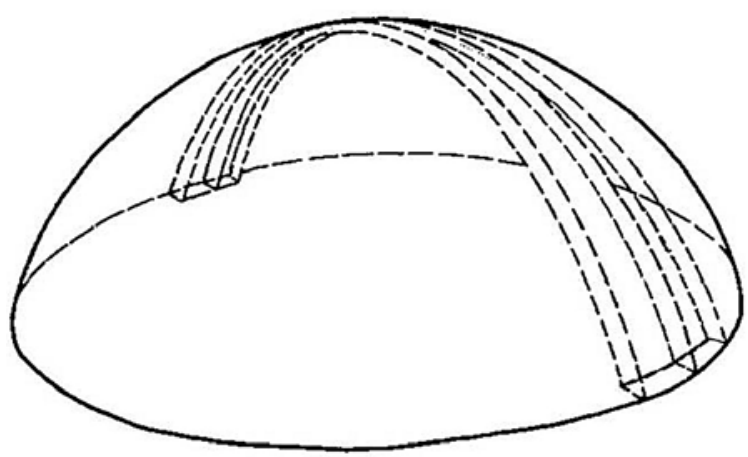

Fonte: REBELLO, 2000

Sendo assim, para entendermos as funções estruturais de uma cúpula devemos analisar primeiro o funcionamento dos arcos e paralelamente dos cabos, que invertidos simetricamente em relação ao eixo horizontal, gera um sistema estrutural análogo, os arcos.

Se pegarmos um cabo fixo nas duas extremidades e nele aplicarmos um carregamento este assumirá uma forma de equilíbrio que irá variar de acordo com a quantidade e a posição da(s) carga(s) aplicada(s). A forma assumida pelo cabo é o caminho que as forças - no caso dos cabos, apenas esforços de tração simples percorrem até os apoios. Esse caminho recebe o nome de funicular (Rebello, 2000).

Ao invertermos simetricamente esse sistema, em relação ao eixo horizontal, temos um arco funicular (Fig. 6). Os arcos funiculares estão sujeitos a esforços inversos ao dos cabos, ou seja, um cabo com formato funicular gera esforços somente de compressão simples. Com essa descoberta o homem foi capaz de construir grandes vãos com um material muito comum e primitivo, o bloco de pedra, que possui uma grande resistência à compressão, mas é muito frágil à tração.

Assim, quanto mais próximos da forma funicular estiver o arco menos esforços de tração ocorrerão e será possível a utilização de menos material - espessuras menores - para vãos maiores. Cada vez que o funicular das cargas desvia-se do eixo do arco originam-se esforços de flexão, sendo que quanto maiores forem os desvios maiores serão esses esforços.
Figura 6: Formas Funiculares - Cabos e Arcos.
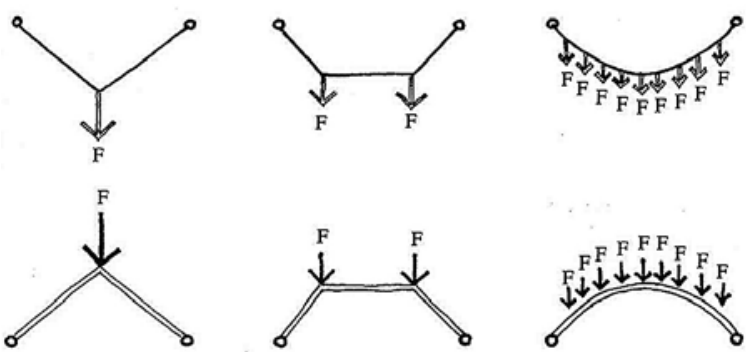

Fonte: adaptado de REBELLO, 2000.
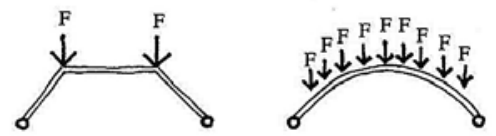

Sabe-se que para uma cúpula estar totalmente comprimida, ela deve ter uma abertura angular de aproximadamente $104^{\circ}$, isto é, a transição entre os esforços de compressão e tração se ocorre com $52^{\circ}$ (considerando um ângulo medido do topo para a base) (Rebello, 2000). No Museu Nacional, Niemeyer e Sussekind utilizaram deste princípio para gerar a forma da cúpula, a angulação no caso do Museu é de cerca de $58^{\circ}$, como pode ser observado na Figura 7.

Figura 7: Corte Esquemático do arco gerador da cúpula do Museu Nacional.

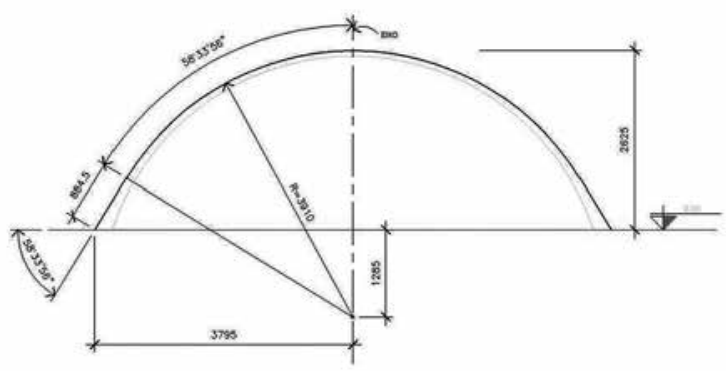

Fonte: Casuarina Consult. LTDA.

Além dessa reação existe também a tendência de abertura na base dos arcos carregados. Isso gera reações horizontais indesejadas nos apoios do arco. Essas reações são forças horizontais inversamente proporcionais à flecha do arco (Figura 8), arcos abatidos têm força horizontais maiores das bases do apoio que arcos menos abatidos, por isso a seção transversal nos arcos abatidos serem maiores que nos marcos de flechas maiores. A relação ideal entre flecha e vão é mostrada na fórmula abaixo:

Onde:

$\mathrm{f}=$ Flecha

$\mathrm{L}=\mathrm{Vão}$

Figura 8: Reações horizontais na base do arco.

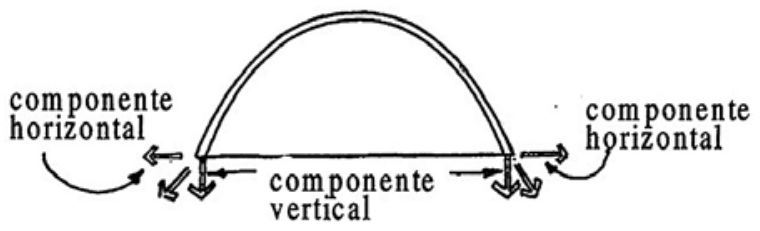

Fonte: Rebello, 2000 
Uma cúpula, como visto, é formada pela sucessão radial dos arcos, portanto se secionada por planos horizontais apresenta círculos denominados paralelos. Quando secionadas por planos verticais que passam pelo centro dos paralelos, apresenta os arcos meridianos que têm a mesma forma do arco que lhe deu origem, conforme a Figura 9.

Figura 9: Paralelos e Meridianos.

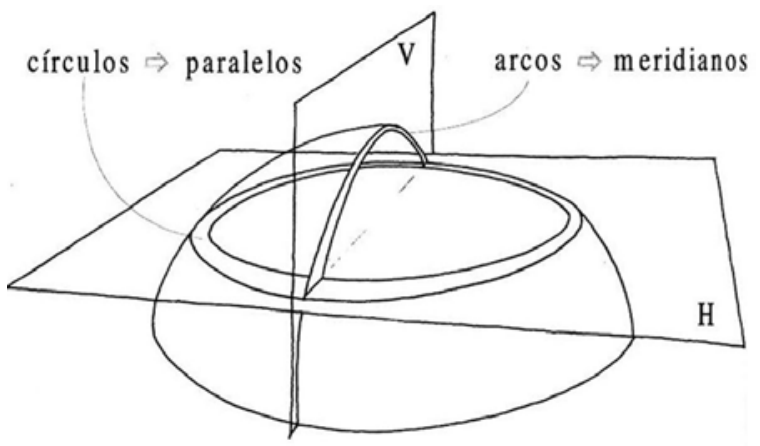

Fonte: Rebello, 2000

Os paralelos comportam-se como anéis de travamento dos arcos dos meridianos e, por isso as cúpulas apresentam um comportamento funicular para qualquer tipo de carregamento, exceto cargas pontuais. Isso se deve ao fato de os paralelos não permitirem livre deformação dos arcos meridianos.

Com isso, para qualquer carregamento, exceto cargas concentradas, os arcos meridianos trabalharão sempre com forças de compressão, permitindo vencer grandes vãos com cúpulas de pequenas espessuras. A possibilidade de flambagem das paredes da cúpula, devido a sua esbelteza, é geralmente muito pequena graças à sua dupla curvatura.

A planta de formas da cobertura do Museu Nacional evidencia a presença da sucessão dos arcos paralelos, compondo a cúpula (Figura 10).

Apesar do desempenho da cúpula ser ideal apenas para cargas distribuídas uniformemente, Oscar Niemeyer aplicou, no último piso, um mezanino apoiado em tirantes fixados nos arcos da cobertura. Esta decisão gerou esforços pontuais bem definidos no conjunto, o que, por sua vez, geraram esforços de flexão na estrutura.

Nesse caso, como a cúpula não apresenta somente esforços de compressão, os esforços de flexão geram grandes esforços horizontais nos apoios causando uma tendência da cúpula aumentar de tamanho na base. Essa tendência gera um efeito chamado de "Perturbação de Borda" (REBELLO, 2000). A perturbação de borda (Figura 11) é o aparecimento de momento fletor na borda da cúpula, indicado por uma brusca mudança na curvatura, já que não há possibilidade de deslocamentos na base do arco.

Figura 10: Planta de Cobertura.

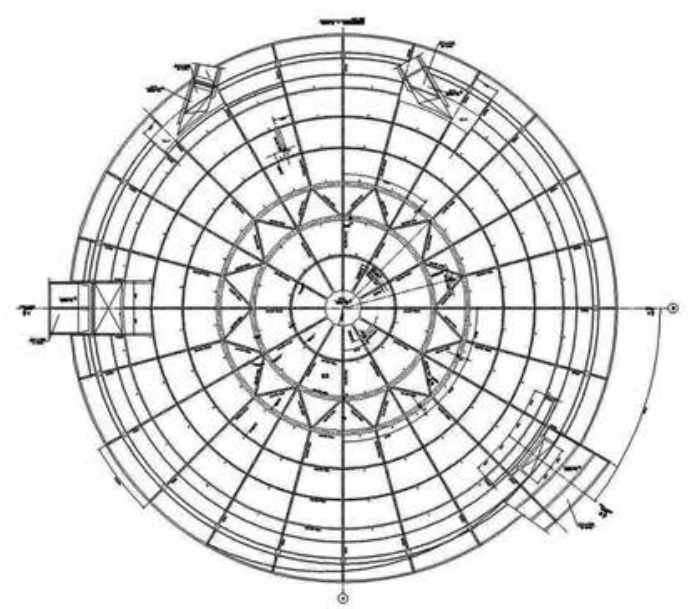

Fonte: Casuarina Consultoria LTDA.

Figura 11: Perturbação de Borda.
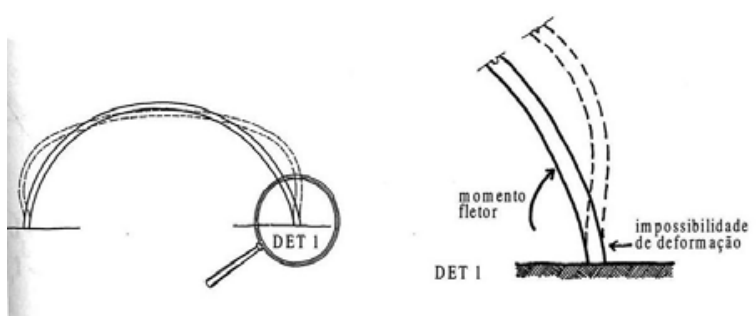

Fonte: REBELLO, 2000

Para combater esse fenômeno, José Carlos Sussekind se valeu de duas soluções. Primeiro, como pode ser notado na foto da Figura 12, ele utilizou um grande anel de compressão na base da cúpula e, além disso, também aumentou a espessura da cúpula junto ao apoio, usando inclusive uma parede dupla nessa região (Figura 13). 
Figura 12: Execução das Fundações e do Anel de Compressão na base da cúpula.

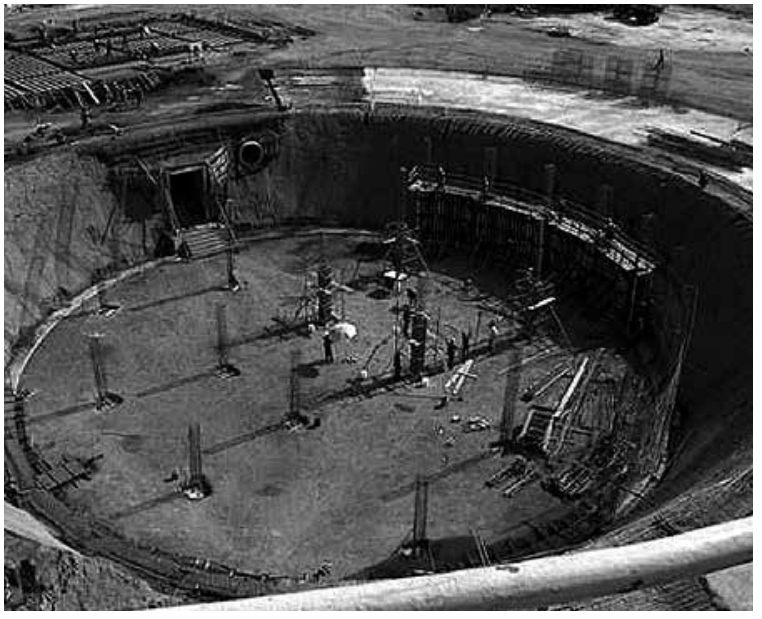

Fonte: VIA Engenharia.

Figura 13: Execução da base da cúpula - parede dupla.

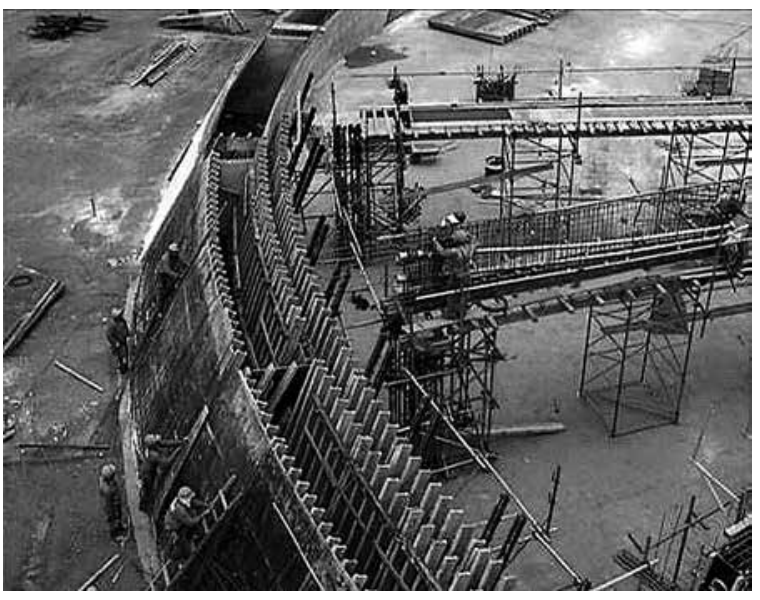

Fonte: VIA Engenharia.

Outro grande desafio para o engenheiro José Carlos Sussekind foi a grande laje do pavimento de exposições, pois esta laje de 80 metros de diâmetro não possui nenhum apoio central, deixando livre todo o diâmetro do meridiano. Isto permite total liberdade para a instalação dos auditórios no pavimento inferior. Esse desafio apareceu no momento em que o arquiteto Oscar Niemeyer resolveu dobrar o tamanho da cúpula, dobrando também o tamanho da laje.

Este grande vão foi possível graças ao conjunto de vigas radiais (Figura 14) que, nas extremidades se apóiam nos arcos da cúpula e, no centro, comprimem um maciço de concreto suspenso.

Acima desse nível está o mezanino, sustentado pelos tirantes na estrutura da própria cúpula. A laje desse mezanino possui uma forma orgânica, cheia de curvas e totalmente livre de pilares. A planta de formas do mezanino mostra o desenho das vigas, também sinuosas nessa laje, que permitiram a sustentação da forma curva desejada pelo arquiteto (Figura 15).

Na sequência (Figura 16) o corte mostra os tirantes que sustentam a laje do mezanino e o ponto de contato deles na estrutura da cúpula. Essa estrutura teve que ser reforçada nesses pontos, como se vê no detalhe (Figura 17).

Figura 14: Vigas Radiais do pavimento de exposições.

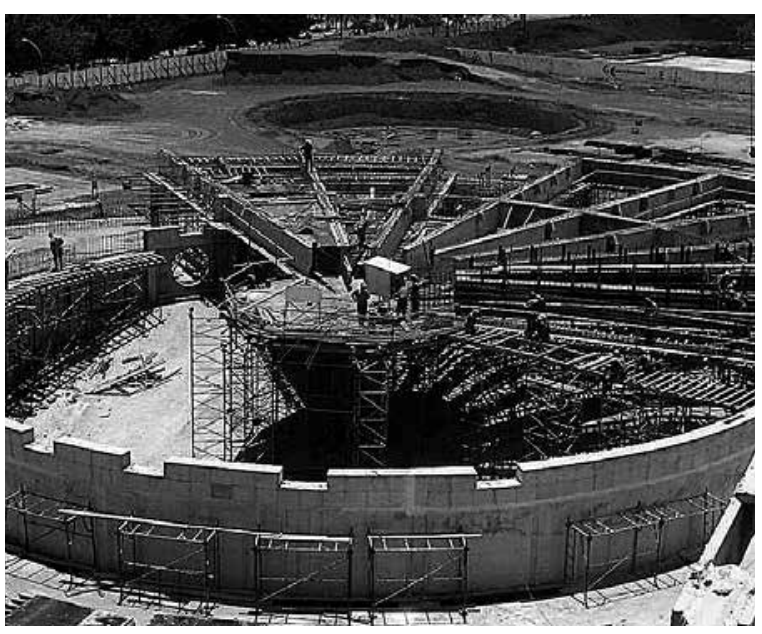

Fonte VIA Engenharia.

Figura 15: Planta de Formas do Mezanino.

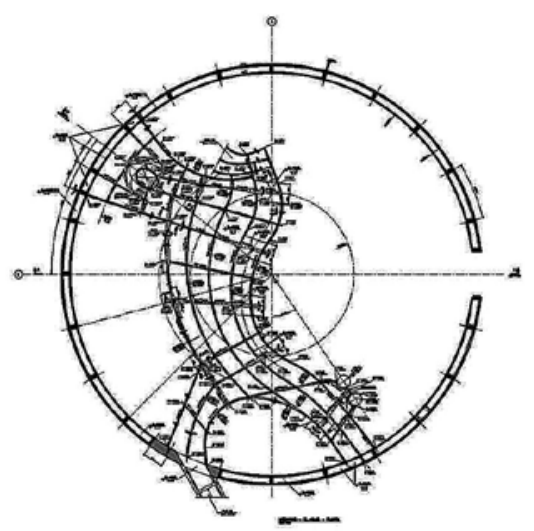

Fonte: Casuarina Consultoria LTDA.

Figura 16: Corte Longitudinal.

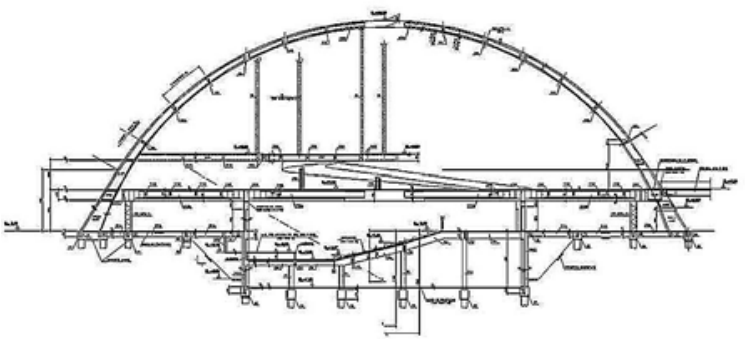

Fonte: Casuarina Consultoria LTDA. 
Figura 17: Detalhes dos Tirantes.

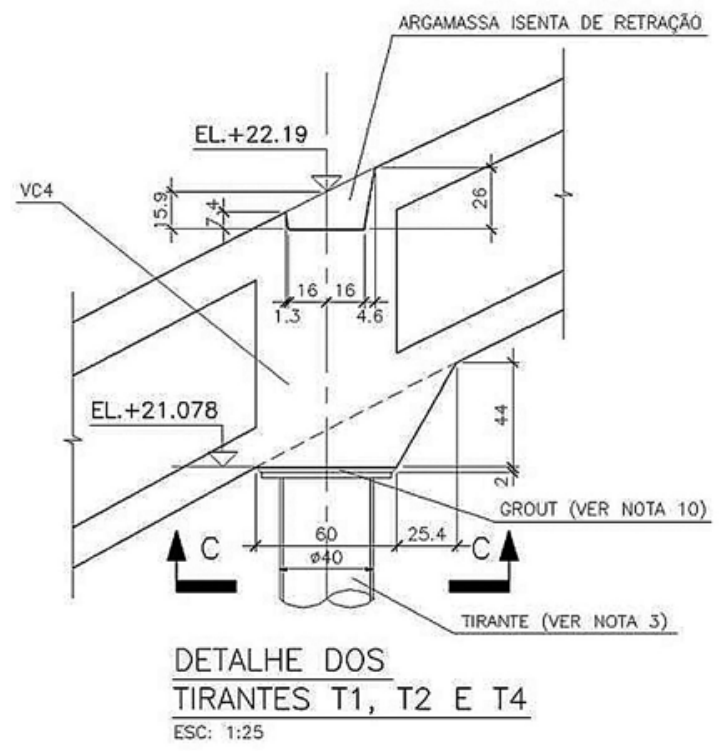

Fonte: Casuarina Consultoria LTDA.

Para o engenheiro José Carlos Sussekind essa solução estrutural, encontrada ainda quando o projeto previa um segundo mezanino para o restaurante, foi um dos pontos mais importantes do projeto, pois pode evidenciar o grande plano livre do salão de exposições.

Conversamos e chegamos a uma ótima solução, que acho útil registrar: vamos usar e reforçar a cúpula para, também, suportar as lajes do mezanino, do restaurante e do mirante, suspendendoas (até a cúpula) por intermédio de tirantes. Com isso o nível principal (térreo) das exposições exibirá um quase inacreditável diâmetro livre de 80 metros, assim criando um espaço cuja amplitude espantará os visitantes." (José Carlos Sussekind, em Conversa de Amigos, Sussekind, J. Carlos e Niemeyer, Oscar, Ed. Revan, 2002, p.73).

Outro elemento que chama atenção na arquitetura do museu é a rampa externa (rampa 3), que une o piso principal do salão de exposições com o mezanino. Essa rampa tem um balanço de quase 20 metros que também necessitou de atenção especial do calculista, que achava ser esse seu único desafio estrutural no projeto, isso antes do projeto ser modificado, quando este ainda previa uma cúpula de "apenas" 40 metros, com lajes de, no máximo, 40 metros de vão.

Essa rampa 3, que sai da cúpula em curva, retornando à mesma no andar superior, não possui nenhum apoio a não ser a própria parede da cúpula, no início e no final da rampa. Ela se sustenta longitudinalmente com duas vigas de borda que variam de $1,25 \mathrm{~m}$ a $1,85 \mathrm{~m}$ de altura, dos quais $0,85 \mathrm{~m}$ já servem como guarda corpo. Transver- salmente ela se apoia em uma sequência de 11 vigas dispostas de forma radial ao longo do comprimento da rampa (Figura 18 e 19).

Figura 18: Planta de Formas da Rampa 3.

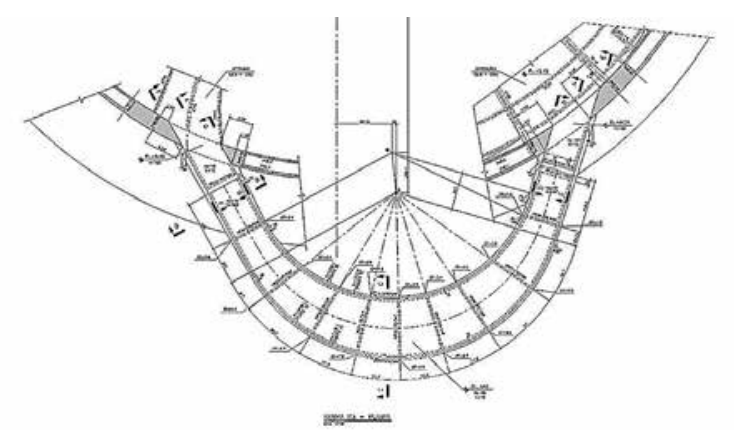

Fonte: Casuarina Consultoria LTDA.

Figura 19: Concretagem da Rampa 3.

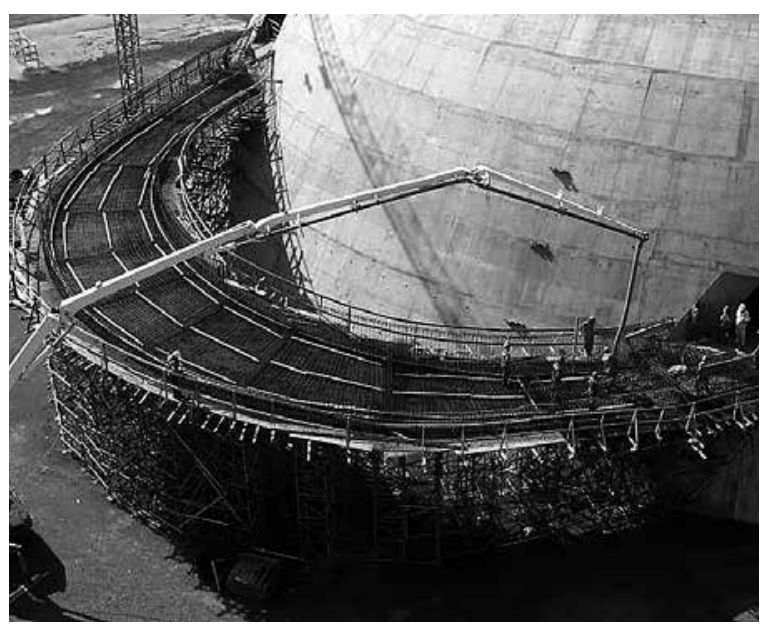

Fonte: VIA Engenharia.

\subsection{Análise Estrutural - utilizando pa- drões atuais de modelagem}

Com base nos dados levantados nos desenhos técnicos da estrutura do Museu Nacional - planta de formas, cortes, desenhos arquitetônicos, etc - cedidos pela empresa Casuarina Consultoria LTDA e pela construtora VIA Engenharia, foi modelado, no programa SAP 2000, versão 11, o sistema estrutural do Museu Nacional. A Figura 20 mostra a montagem do sistema estrutural em estudo. 
Figura 20: Montagem passo a passo do sistema estrutural do Museu Nacional.

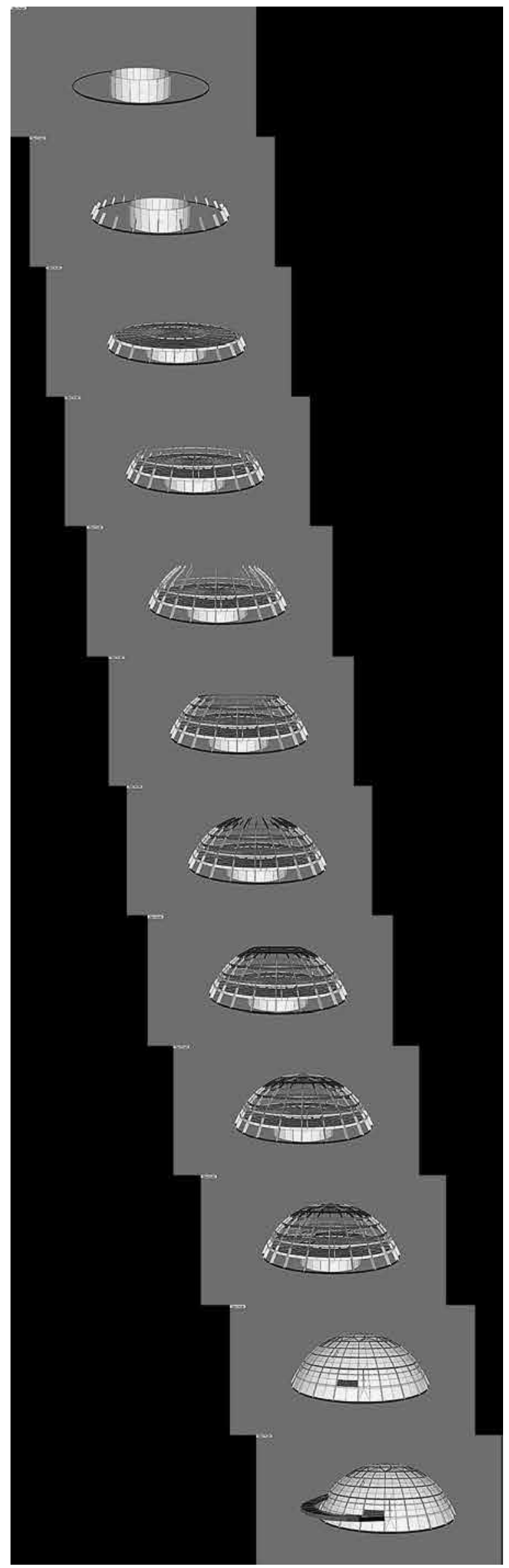

Fonte: programa SAP 2000.
Os valores utilizados no modelo em estudo foram tabulados na Tabela 1. Para essa análise estrutural, qualitativa, foram consideradas apenas o peso próprio da estrutura. Para simplificar a leitura dos resultados foram desconsiderados no modelo as rampas 1 e 2, respectivamente a rampa de acesso ao Pavimento de Exposições e a rampa que liga esse pavimento ao mezanino.

Tabela 1: Dimensões da estrutura do Museu Nacional, levantadas para análise estrutural.

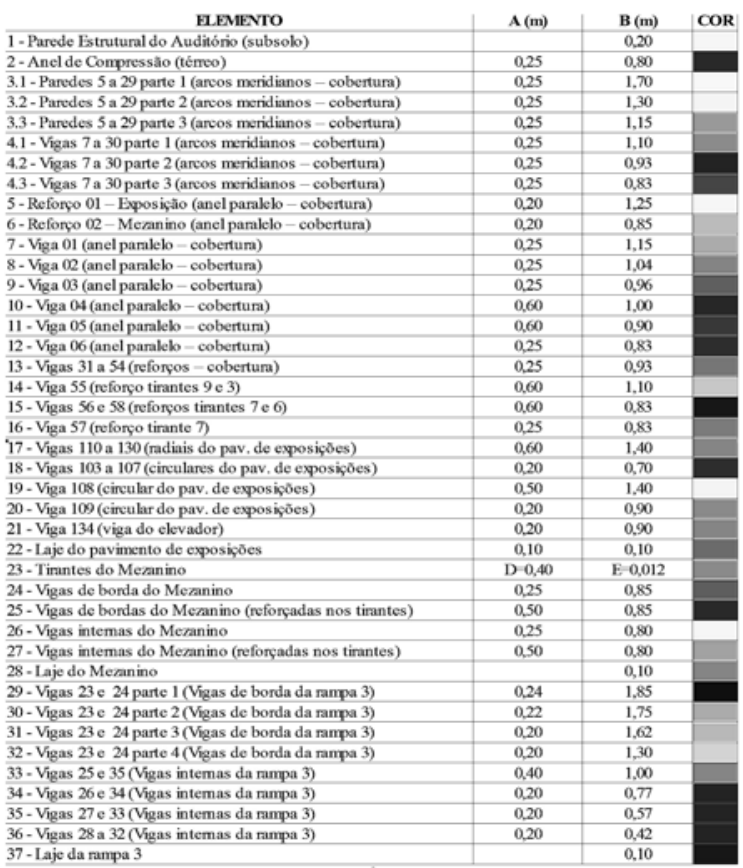

Fonte: Dados do autor.

Podemos observar no diagrama de Forças Normais das vigas, Figura 21, que os arcos meridianos da cobertura do Museu Nacional estão sob compressão, na cor vermelha. De acordo com os resultados obtidos através do programa SAP 2000 , os valores variam de 264tf. na base dos arcos e aproximadamente 40tf. no topo da estruGra, no encontro dos arcos meridianos.

Figura 21: Diagrama de Forças Normais da cobertura do Museu Nacional.

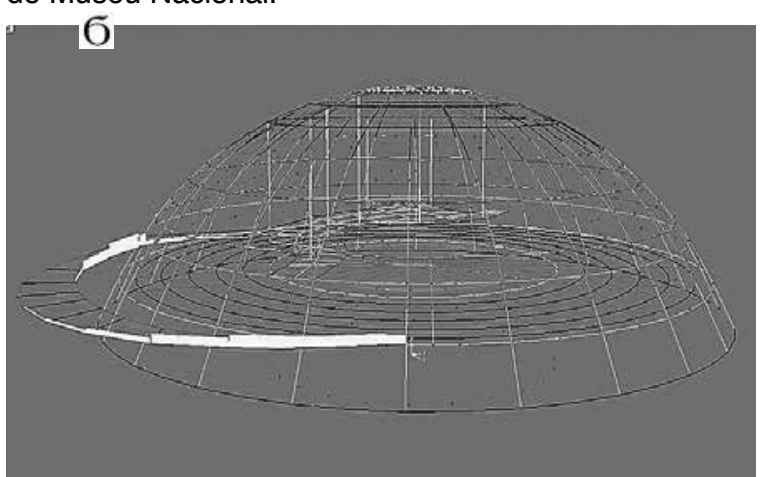

Fonte: programa SAP 2000.

O mesmo diagrama acima mostra as forças normais da rampa 3 , externa à estrutura da cúpula. 
Notamos que na viga 23, viga de borda da rampa, mais próxima à cúpula os valores obtidos variam entre -790tf (tração, mostrada em amarelo) no ponto em que a viga se engasta à estrutura da cúpula na altura do Mezanino, e 718tf (compressão, mostrada em vermelho) no ponto oposto, onde a viga se une à estrutura na altura do Pavimento de Exposições.

Já a viga 24, viga de borda externa da rampa, comporta-se de maneira oposta. No ponto onde esta se une ao Pavimento de Exposições, o diagrama mostra uma tração de cerca de -500tf., enquanto que no ponto onde esta se une ao Mezanino o valor que temos é de 480tf. (compressão).

Ainda analisando o diagrama de forças normais, com detalhe das reações nos tirantes que suportam o mezanino (Figura 22), notamos que eles sofrem uma tração (amarelo) de 150tf.

Figura 22: Diagrama de Forças Normais dos tirantes do mezanino do Museu Nacional.

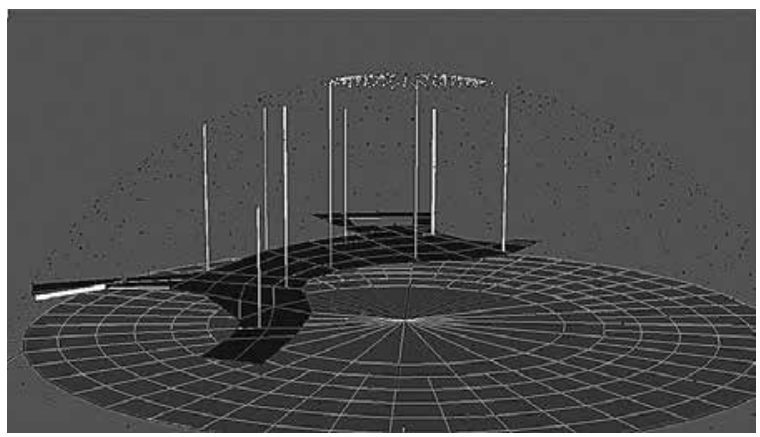

Fonte: Programa SAP 2000

Com base nesses dados podemos verificar qual a área de aço necessária para os tirantes, através da fórmula baixo.

$$
\sigma=\mathrm{F} / \mathrm{A}
$$

Onde:

$$
\text { =Tensão }
$$

$\mathrm{F}=$ Força

$A=A ́ r e a$

Com $=2500 \mathrm{Kgf} / \mathrm{cm}^{2}$, com coeficiente de segurança de $40 \%$ e $\mathrm{F}=150 \mathrm{tf}$, temos uma área de $150 \mathrm{~cm}^{2}$. Esse resultado é consistente com a dimensão adotada para o tirante em questão, um tubo de aço SAC-250, com $40 \mathrm{~cm}$ de diâmetro e $1,5 \mathrm{~cm}$ de espessura $\left(A=152 \mathrm{~cm}^{2}\right)$.

Analisando agora o diagrama de momento fletor, Figura 23, podemos observar uma concentração de momento no encontro da rampa externa (rampa 3) com a estrutura da cúpula, justamente nos pontos onde foram adicionados reforços na estrutura, com paredes de concreto - paredes 15 e 16, no nível de Exposições e
19 e 20, no nível do Mezanino. Os valores observados são: 1580 tf.m no encontro da viga 23 com a estrutura no pavimento de Exposição e 941tf.m no encontro da viga 24 com a estrutura no nível do Mezanino.

Figura 23: Diagrama de Momento Fletor do Museu Nacional.

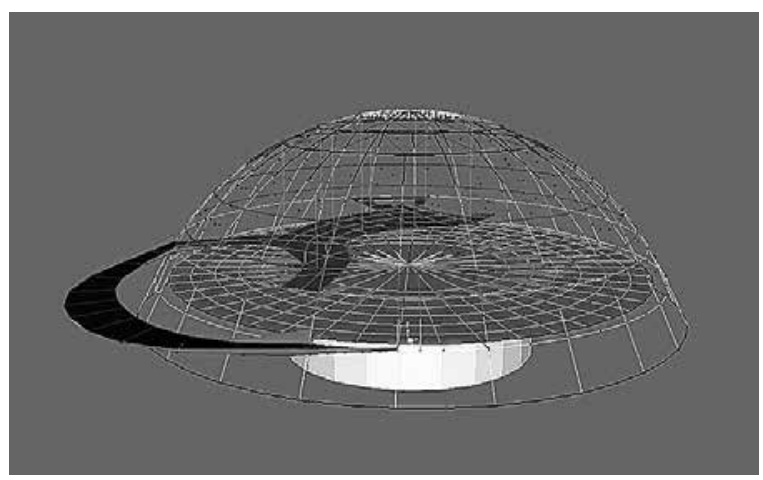

Fonte: Programa SAP 2000.

No diagrama abaixo (Figura 24), Diagrama de Deformações, podemos observar que os deslocamentos da estrutura na cúpula são muito pequenos $-0,02 \mathrm{~cm}$ nos arcos meridianos, na altura do encontro desses com a laje do Pavimento de exposições e $0,1 \mathrm{~cm}$ no topo da estrutura, no encontro dos arcos meridianos.

Figura 24: Diagrama de Deformações do Museu Nacional.

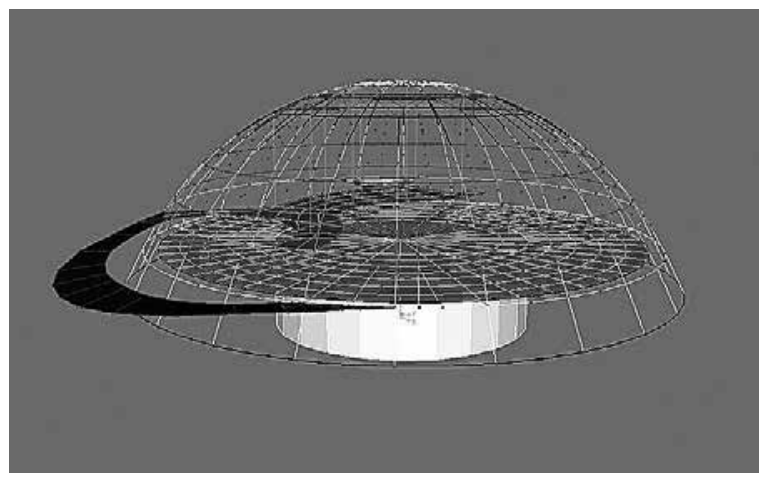

Fonte: Programa SAP 2000.

Em contraste com a estrutura equilibrada da cúpula de cobertura do Museu Nacional, a rampa 3, que possui um balanço de $20 \mathrm{~m}$ para a parte externa da estrutura, apresenta um deslocamento mostrado no gráfico de $10,4 \mathrm{~cm}$ na direção z (vertical).

Outro dado interessante observado nesse gráfico é o alongamento $(\Delta I)$ dos tirantes que suportam o Mezanino. Calculando-se esse valor através da fórmula abaixo para 0 tirante 7 , onde $P=$ $150.000 \mathrm{Kg} ; \mathrm{I}=1622 \mathrm{~cm} ; \mathrm{E}=2.100 .000 \mathrm{Kg} / \mathrm{cm}^{2} \mathrm{e}$ $A=152 \mathrm{~cm}^{2}$, temos um deslocamento de $0,76 \mathrm{~cm}$. No gráfico mostrado acima, os deslocamentos dos tirantes 1 a 9 variam entre $0,4 \mathrm{~cm}$ e $0,6 \mathrm{~cm}$. 


$$
\Delta \mathrm{I}=\text { P.I } / \text { E.A }
$$

Onde:

$\Delta \mathrm{l}=$ Alongamento

$\mathrm{P}=\mathrm{Peso}$

E=Módulo de elasticidade

O Diagrama de Deformações mostra também um deslocamento de $1,5 \mathrm{~cm}$ no centro da laje do Pavimento de Exposições. Esse ponto é o centro de um vão de 34,5 metros sobre o auditório do pavimento térreo.

Podemos notar com essas análises que, assim como outros projetos de Oscar Niemeyer, o projeto do Museu Nacional Honestino Guimarães, apesar de em um primeiro momento apresentar uma forma simples - a cúpula - o arquiteto acrescentou características únicas, exigindo soluções estruturais complexas, que não interferem no resultado da forma arquitetônica, e sim contribuem com ele. Isso só é conseguido por meio de uma total sintonia entre o sistema estrutural adotado e o desenho arquitetônico pretendido, desde o início do processo projetual.

As verificações atendem aos modelos previstos em norma - que atualmente, já preveem a análise de elementos finitos (Norma NBR 6118) - como no exemplo os tirantes, observando os deslocamentos e esforços.

O modelo numérico empregado, de elementos finitos para casca, do programa SAP 2000, consiste da teoria de casca de Mindlin que foi associado ao pórtico espacial, gerando uma análise completa da estrutura em 3D.

Os resultados mostram que o modelo numérico empregado confirma a proposta inicial de estrutura sugerida pela equipe técnica.

\section{Conclusões}

Oscar Niemeyer sempre mostrou em suas obras, inclusive no seu processo criativo, que a arquitetura e a estrutura nascem juntas, não são elementos distintos da construção. Apesar dessa estreita relação entre arquitetura e estrutura nos projetos de Niemeyer, o que se vê na maioria dos casos entre arquitetos e engenheiros é uma distância muito grande. Arquitetos que projetam sem entender a estrutura que suportará a forma sugerida e engenheiros que não demonstram atrativo estético em seus trabalhos.

Os engenheiros que trabalharam com Niemeyer também exerceram um importante papel na formação do arquiteto, conseguindo soluções estruturais inéditas em diversas épocas para possibilitar a realização da inventividade formal da arquitetura de Niemeyer. E, como o próprio arquiteto diz, Niemeyer teve a sorte de trabalhar com grandes nomes da engenharia nacional, como Emílio Baumgart, Bruno Contarini, Joaquim Cardozo e José Carlos Sussekind. Com eles o arquiteto pode levar ao mundo os avanços tecnológicos que a construção civil nacional fazia, e ainda faz, por intermédio de sua arquitetura.

A presença definidora do sistema estrutural continua acompanhando os trabalhos mais recentes de Oscar Niemeyer, que explora com muito mais simplicidade e experiência os limites e as possibilidades do concreto armado. O Museu Nacional, em Brasília, construído em 2006 é um exemplo disso, com sua forma plástica é definida diretamente por uma cúpula.

Além da cúpula, Niemeyer utilizou outros elementos estruturais para valorizar a arquitetura interna e externa do Museu Nacional, como a grande rampa em balanço que une os dois pavimentos internos através de um "passeio" pela exuberante paisagem da explanada dos Ministérios. Internamente, tem-se um grande vão livre com 80 metros de diâmetro conseguidos através da sustentação do mezanino por tirantes fixados na própria cúpula de cobertura.

Com base em dados coletados junto à construtora responsável pela obra, tivemos como descrever com precisão a estrutura do museu e assim pudemos analisar essa estrutura em vários aspectos com o auxílio de ferramentas computacionais, como o programa SAP 2000, utilizado nesse estudo de caso. Por meio das análises feitas no programa computacional, podemos destacar a função estrutural de cada elemento que visualmente tem grande função estética.

Essas análises, tanto históricas quanto técnicas de grandes obras de Oscar Niemeyer, e também da arquitetura nacional, contribuem para um entendimento da importância do conhecimento técnico e tecnológico para a produção de uma arquitetura de boa qualidade e engenharia de alta tecnologia.

\section{Referências}

MACIEL, Fabiano; SASHA. Oscar Niemeyer, A Vida é um Sopro. Documentário. Europa Filmes, 2007.

REBELLO, Y. C. P. A Concepção Estrutural e a Arquitetura. Editora Zigurate, São Paulo, 2000.

SERAPIÃO, Fernando. Museu Nacional Honestino Guimarães, Brasília. Revista Projeto Design, edição 326 Abril de 2007.

SUSSEKIND, José Carlos; Niemeyer, Oscar. Conversa de Amigos: correspondências entre Oscar Niemeyer e José Carlos Sussekind. Ed. Revan, Rio de Janeiro, 2002. 